\title{
Prevención de infecciones asociadas a catéteres vasculares centrales
}

\author{
POLA BRENNER F. ${ }^{1}$, GUILLERMO BUGEDO T. ${ }^{2}$, DOLORES CALLEJA R. ${ }^{1,3}$, \\ GLADYS DEL VALLE M. ${ }^{1,4}$, ALBERTO FICA C. ${ }^{5}$, M. ELIANA GÓMEZ O. ${ }^{1,6}$, \\ LEONOR JOFRÉ M. ${ }^{7}$ y LUZA SUTIL P. ${ }^{1,8}$.
}

\section{Prevention of catheter related infections}

\section{Introducción}

Las infecciones del torrente sanguíneo asociadas a un catéter vascular central (CVC) son un problema de salud relevante en Chile. El último informe de vigilancia epidemiológica de infecciones intrahospitalarias del Ministerio de Salud de Chile ${ }^{1}$, señaló para el año 2000, una tasa de 3,7 infecciones por 1.000 días de CVC en adultos y 4,6 eventos por 1.000 días para pacientes pediátricos, ocupando Staphylococcus aureus la primera causa en adultos o niños (34 y 24,7\%, respectivamente). Para el mismo año, las tasas de infecciones del torrente sanguíneo asociadas a nutrición parenteral o a hemodiálisis, fueron similares (4,1 y 3,8 por 1.000 , respectivamente). Salvo la disminución de estas tasas observadas en los Servicios de Medicina, Cirugía o Neonatología en los últimos años, la magnitud de este problema no decrece en general y continúa representando un riesgo importante, ya sea si el catéter es utilizado para monitorización hemodinámica, administración de fármacos, hemoderivados, nutrición parenteral o hemodiálisis.

Aunque los datos presentados por el MINSAL sobreestiman de alguna manera la verdadera incidencia de bacteremias asociadas a catéteres vasculares centrales (CVCs) debido a la utiliza- ción de definiciones amplias en un sistema de vigilancia activa, ello no disminuye la gran importancia de estas infecciones en el trabajo clínico cotidiano.

La incidencia de infecciones asociadas al cateterismo vascular varía dependiendo de factores del huésped, del catéter y la intensidad de la manipulación. Factores específicos descritos corresponden al material del catéter, ubicación, método de instalación, instalación electiva o de urgencia, número de lúmenes, duración de la cateterización y características del huésped (quemados, recién nacidos de muy bajo peso) $)^{2,3}$. En general las tasas son mayores en pacientes bajo $1.000 \mathrm{~g}$ de peso en unidades intensivas neonatológicas y pacientes quemados, y son menores en pacientes adultos cardioquirúrgicos ${ }^{2}$.

Las infecciones del torrente sanguíneo asociadas a CVCs representan un aumento de la morbilidad, de los costos de la atención de pacientes y en una fracción de los casos, tienen una mortalidad atribuible (14 a 24\%) ${ }^{3}$.

Diversas intervenciones para prevenir estas infecciones han sido delineadas y propuestas en diferentes guías extranjeras y en algunas recomendaciones emanadas del MINSAL en nuestro país ${ }^{2}$. Las estrategias de prevención disminuyen significativamente las infecciones asociadas a CVCs.

\footnotetext{
Sociedad Chilena de Control de Infecciones y Epidemiológía Hospitalaria.

Programa de Medicina Intensiva, Hospital Clínico Pontificia Universidad Católica y Sociedad Chilena de Medicina

3 Enfermera Control de Infecciones, Asistencia Pública Dr. Alejandro Del Río.

Enfermera Control de Infecciones, Hospital Luis Calvo Mackenna.

Comité Infecciones Intrahospitalarias, Hospital Clínico Universidad de Chile.

Enfermera Control de Infecciones, Hospital del Trabajador, Asociación Chilena de Seguridad.

Hospital Clínico Universidad de Chile. Residente Hospital Luis Calvo Mackenna.

Enfermera Epidemióloga, Clínica Las Condes.
} Intensiva.

Recibido: 8 enero 2003

Aceptado: 4 marzo 2003 


\section{Patogenia}

Las infecciones asociadas a CVCs pueden ser provocadas por la migración de microorganismos cutáneos desde el sitio de inserción, la contaminación de las conexiones del catéter, lo que favorece a su vez la colonización endoluminal, y por contaminación de los fluidos en infusión, aunque este último mecanismo es muy infrecuente. El CVC puede a su vez ser colonizado en forma secundaria por bacteriemias. De esta manera, la piel y la conexión son las principales fuentes de la colonización del catéter, predominando los agentes cutáneos en los CVCs de corta duración y los adquiridos por contaminación de la conexión en los de larga duración. La adherencia y colonización de los microorganismos al catéter con formación de una matriz biológica, representa uno de los eventos iniciales que conducen posteriormente a la septicemia relacionada al catéter. Dependiendo de las especies involucradas, algunas moléculas de adhesión específicas participan en la adherencia inicial de las bacterias al material inerte ${ }^{4}$. Por otra parte, el material extracelular (biopolímeros) sintetizados por algunas de estas especies facilita la persistencia del agente en la superficie del CVC y la evasión de la respuesta inmune. El material de los CVCs también influye en esta colonización ya que algunos tipos de catéteres como los de poliuretano dificultan la adherencia de ciertas especies, Staphylococcus por ejemplo ${ }^{4}$. En contraste, los catéteres de silicona o PVC están asociados a una mayor adherencia para diferentes especies. El tipo de material interfiere también con la respuesta inmune. Por ejemplo la producción de radicales superóxidos es inhibida con catéteres de teflon, PVC o silicona.

La colonización de la superficie del catéter por bacterias interfiere en el tratamiento, no sólo por sus capacidades de evadir la respuesta inmune, sino que también por el incremento sustantivo de las CIMs de diferentes antimicrobianos en estas condiciones. Desde el punto de vista terapéutico, las infecciones asociadas a CVCs colonizados se comportan como infecciones asociadas a cuerpos extraños, lo que determina que el eje del tratamiento deba considerar su remoción o la combinación de antimicrobianos para lograr un efecto sinérgico ${ }^{4}$.

En catéteres de corta duración, la colonización ocurre fundamentalmente desde la superficie externa por microorganismos de la piel del sitio de inserción. En contraste, en los de larga duración, predomina la colonización de la superficie endoluminal. En este último caso, los microorganismos colonizarían la conexión a tra- vés de las manos contaminadas del personal que manipula la conexión.

\section{Prevención de infecciones del torrente sanguíneo asociadas a catéteres vasculares centrales}

Este consenso fue elaborado para uniformar las prácticas de prevención y mejorar la calidad de atención de los pacientes que requieren la instalación de un CVC. Para ello, las intervenciones de prevención de infecciones se analizaron por separado para las etapas de pre instalación, instalación del catéter central y manejo. Las preguntas elaboradas por el grupo se señalan en la Tabla 1.

\section{Intervenciones de prevención antes de la instalación}

\section{¿Tienen importancia los programas de capacitación para prevenir las infecciones asociadas a CVC? ¿Quién debe instalar el catéter vascular?}

Existe una sólida evidencia para recomendar los programas de capacitación en prevención y un entrenamiento formal en la instalación de los CVCs. Por ejemplo, un programa educacional a médicos en entrenamiento logró disminuir la incidencia de infecciones del torrente sanguíneo (ITS) de 4,5 a 2,9 por 1.000 días-catéter, resaltando la importancia de la experiencia del instalador ${ }^{5}$.

La capacitación para la prevención queda respaldada por otro estudio que incluyó charlas educacionales a todos los residentes y enfermeras de la UCI, enfatizando el seguimiento estricto de las normas de manejo y cuidado de los catéteres. Esta práctica estuvo asociada a una disminución en la incidencia de infección en el sitio de entrada del catéter y en las infecciones del torrente sanguíneo $(9,2$ a 3,3 por 1.000 y 11,3 a 3,8 por 1.000 días-catéter, respectivamente) ${ }^{6}$. Por otra parte, dos estudios prospectivos han demostrado que la creación de un equipo de enfermeras ( $I V$ team) especialmente dedicado a la inserción y mantención de accesos vasculares periféricos, estuvo asociada a la disminución de la incidencia de inflamación e infección ${ }^{7,8}$. Según ha revelado un meta-análisis publicado recientemente, los programas de educación contínua logran cambiar la práctica profesional y en algunos casos, mejorar los resultados clínicos 9 .

En nuestro país, la introducción de sistemas globales de acreditación para hospitales en prevención y control de $\mathrm{IIH}$, que incluyen aspectos específicos de capacitación, han estado asociados a una gran reducción de las tasas de diferen- 
Tabla 1. Preguntas formuladas sobre prevención de infecciones asociadas a CVCs

\section{Pre instalación}

¿Tienen importancia los programas de capacitación para prevenir las infecciones asociadas a CVCs? ¿Quién debe instalar el CVC?

¿Existen ventajas relativas para prevenir infecciones al utilizar catéteres venosos centrales sintetizados con un diferente tipo de material?

¿Existen ventajas relativas para prevenir complicaciones infecciosas entre CVCs insertados por vía periférica y los insertados en forma convencional?

¿Ofrece la tunelización de los CVCs un beneficio para disminuir la frecuencia de infecciones asociadas a estos catéteres?

¿Existen diferencias objetivas y significativas en la tasa de infecciones al considerar el sitio anatómico de inserción de un CVC convencional?

¿Debemos utilizar catéteres vasculares impregnados con algún antimicrobiano y/o antiséptico para optimizar la prevención de infecciones asociadas? ¿Es una estrategia costo-efectiva?

¿Aumenta el número de lúmenes del dispositivo el riesgo de infección?

¿Es posible plantear una inmunización activa contra Staphylococcus aureus, uno de los microorganismos más importantes de bacteremia o sepsis asociada a CVC?

¿Debemos utilizar ultrasonido al instalar un CVC?

\section{Instalación}

¿En qué recinto físico se debe instalar el CVC?

¿Cuáles son las barreras y la extensión del campo estéril que deberían ser utilizadas en la instalación de un CVC para prevenir las infecciones asociadas?

¿Existen diferencias objetivas para prevenir infecciones asociadas a CVC según el tipo de antiséptico con el que se prepara la piel?

¿Existe un número de venopunciones sobre el cual aumenta el riesgo de infecciones?

¿Existen diferencias significativas entre diferentes sistemas de protección del sitio de inserción?

\section{Post instalación y manejo del CVC}

¿Con qué frecuencia deberían ser cambiados los CVCs para prevenir infecciones? ¿Representa el recambio por la técnica de Seldinger un mayor riesgo de infecciones?

¿Tiene utilidad el uso de heparina en la prevención de infecciones asociadas a CVCs?

¿Tiene utilidad la profilaxis local o sistémica con antimicrobianos para prevenir las infecciones asociadas a CVCs?

¿Con qué frecuencia deben cambiarse los equipos de administración de fluidos?

¿Tienen utilidad los sistemas de acceso sin aguja o con válvulas de reflujo para prevenir infecciones asociadas a CVCs?

tes infecciones asociadas a procedimientos invasores o quirúrgicos. Actualmente no se concibe un programa de prevención sin la inclusión de un proceso de capacitación.

\section{Recomendaciones:}

- Las personas involucradas en la instalación y manejo de CVCs deben estar debidamente capacitadas en el tema y manejar específicamente los aspectos de indicaciones de uso, instalación con técnica aséptica, manejo y medidas generales de prevención (IA).

- Esta capacitación debe abarcar a todo el personal de salud, profesional universitario o paramédico, involucrado en la instalación, vigilancia o manejo de ellos (IA).

- Las personas que instalan CVCs deben tener un entrenamiento práctico inicial con supervisores más experimentados (IA).

\section{¿Existen ventajas relativas entre catéteres vasculares centrales transitorios con diferente}

\section{material de síntesis para prevenir las} infecciones asociadas a estos dispositivos?

La mayor parte de los catéteres venosos centrales que se usan actualmente son de poliuretano, debido a que se han asociado en estudios no comparativos a una menor frecuencia de infecciones que los catéteres de PVC o de polietileno². In vitro estos catéteres dificultan en mayor grado la adherencia de algunas especies bacterianas que los catéteres de silicona o PVC. Por otra parte, algunos aspectos de la respuesta inmune como la síntesis de radicales superóxidos es inhibida por teflón, PVC o silicona, aunque la relevancia clínica de este aspecto no ha sido evaluada ${ }^{4}$. Los catéteres de PVC y polietileno tienen además el inconveniente de su rigidez, lo que facilita su fractura y su mayor trombogenicidad en comparación a los de poliuretano ${ }^{10}$. A pesar de no contar con estudios comparativos directos, estos antecedentes hacen recomendable el uso de catéteres de poliuretano sobre los otros tipos (IIIB). 


\section{¿Existen ventajas relativas entre catéteres venosos centrales transitorios insertados por una vía convencional y aquellos insertados periféricamente para prevenir las infecciones asociadas a estos dispositivos?}

Los CVCs son insertados habitualmente en forma directa en una vía central mediante un acceso percutáneo (yugular interno, subclavio o femoral). Se dispone también de CVCs que pueden ser instalados por vía periférica (catéter central periféricamente instalado - CCPI) en la vena basílica, cefálica o en las venas braquiales. Estos últimos presentan varias ventajas potenciales. Pueden ser insertados en la cama del paciente y por profesionales no médicos. No presentan riesgos de neumotórax y los riesgos de hemorragia son muy bajos. Constituyen una alternativa a los catéteres centrales convencionales y los catéteres tunelizados, tanto para la administración de fluidos como para alimentación parenteral total. El tiempo de duración es variable. Los estudios en general presentan promedios de alrededor de 30 días (rango entre 1 y 451 días) ${ }^{11}$.

La mayoría de los estudios publicados sobre estos dispositivos corresponden a estudios descriptivos donde se muestran experiencias en el uso de estos catéteres tanto en servicios pediátricos como de adultos. Estudios de grandes series muestran tasas de bacteriemia asociadas muy bajas, y en general, menor a las bacteriemias asociadas a CVCs convencionales. Basados en estos estudios, en muchas publicaciones se ha concluido que se trata de una intervención de bajo riesgo de bacteriemia asociada y que es costo beneficio favorable ${ }^{10-20}$. Para las complicaciones no infecciosas se mencionan tasas de flebitis por contacto, en general mayor a lo que ocurre con CVCs convencionales y en algunos casos fallas en la inserción relacionadas en general con experiencia del operador ${ }^{10,11,13-15,17-19,21,22}$.

Existen pocos estudios randomizados que hayan comparado los resultados en términos de bacteriemia en CCPI con otros CVCs o con catéteres centrales percutáneos ${ }^{23-25}$. Estos estudios no muestran diferencias en la tasa de bacteriemia asociadas aunque los resultados sobre complicaciones no infecciosas tales como tromboflebitis, mal posicionamiento o intentos fallidos, han sido discordantes ${ }^{23-25}$. En estudios de cohortes prospectivas no randomizados, no se han encontrado diferencias en las tasas de bacteriemias cuando se comparan CCPI con CVCs convencionales ${ }^{26-34}$ aunque en un estudio fue mayor la tasa de flebitis y mal funcionamiento con $\mathrm{CCPI}^{27}$. Todos los estudios muestran que el uso de CCPI es costo/beneficio favorable ex- cepto en un estudio donde los autores concluyen que debido al alto número de intentos fallidos y alta tasas de tromboflebitis, la cateterización convencional por vía yugular o subclavia podría ser más ventajosa ${ }^{25}$.

La instalación del CCPI está influenciada por la habilidad y destreza del equipo de enfermería que lo instala; no hay estudios randomizados o controlados al respecto pero sí observacionales midiendo las tasas de complicaciones antes y después de período de adiestramiento, los que muestran una disminución de las complicaciones mecánicas de 20,4 a 13, 2 por 1.000 días catéter y una tasa similar de infecciones ${ }^{26}$.

\section{Recomendaciones:}

- Los CCPI son una alternativa a los catéteres venosos centrales convencionales y no representan un mayor riesgo de bacteremia (1A).

- Los CCPI pueden ser insertados por profesionales no médicos en la cama del paciente. Esto no representa un mayor riesgo de bacteriemia ni reacciones adversas. Sin embargo, deben ser insertados por profesionales capacitados y entrenados especialmente para este fin. Su competencia debe ser evaluada por programas de supervisión periódicos (1B).

- No hay evidencia que indique que la colocación de CCPI deba ser efectuada bajo fluoroscopia o ecografía, sin embargo, se debe asegurar el control de la posición adecuada del CCPI luego de la instalación (IA).

- Debido a que el riesgo asociado a complicaciones no infecciosas no está claramente definido para este tipo de catéteres, se debe evaluar la frecuencia de estos eventos y su relación costo-beneficio a nivel local (IIIA).

\section{¿Ofrece la tunelización de los CVCs un beneficio para disminuir la frecuencia de infecciones asociadas a estos catéteres?}

La tunelización utiliza un trayecto subcutáneo de algunos centímetros antes de la inserción del $\mathrm{CVC}$ al torrente venoso. El objetivo es retardar la migración exoluminal de las bacterias hacia el extremo distal del catéter y disminuir la tasa o riesgo de bacteriemia. Su aplicación cobra sentido en catéteres destinados a un uso prolongado.

Un meta-análisis desarrollado con 7 trabajos seleccionados, no logró demostrar un efecto protector de esta estrategia al analizar la tunelización en posición subclavia ${ }^{35}$. Sólo se dispone de un trabajo comparativo entre CVCs tunelizados y convencionales para la posición yugular interna y este trabajo demuestra una ventaja significativa de la tunelización para pacientes adultos en unidades críticas ${ }^{36}$. Las complicaciones no infeccio- 
sas asociadas a la tunelización no han sido rigurosamente evaluadas y algunos estudios indican una mayor frecuencia de neumotórax, punción arterial o hematoma del trayecto del túnel para la posición subclavia. Para la vía yugular interna, la tunelización se acompaña de una mayor frecuencia de punciones y dificultades para conducir el catéter. La tunelización de un CVC por vía femoral ha demostrado un menor riesgo de infecciones en comparación a los catéteres convencionales ${ }^{37}$. Un estudio reciente en pacientes pediátricos comparando CVCs tunelizados versus no tunelizados en posición femoral no logró demostrar diferencias en las tasas de bacteriemias ${ }^{38}$.

Recomendaciones:

- No se recomienda la aplicación rutinaria de la tunelización en la instalación de CVC por vía subclavia (IA).

- La tunelización en CVC por vía yugular interna no está claramente recomendada debido a la falta de información sobre las complicaciones no infecciosas asociadas a esta inserción, las que pudieran sobrepasar las ventajas obtenidas en la prevención de infecciones. Por otra parte, el simple refuerzo de la técnica aséptica en la instalación del catéter o el cuidado efectuado por personal altamente entrenado, podrían reducir notoriamente la tasa de sepsis asociada a un CVC convencional y hacer innecesaria la tunelización (IIB).

- En caso de un acceso venoso femoral en pacientes adultos críticos, éste debe mantenerse por el menor tiempo posible. En casos de uso prolongado, se debe preferir la tunelización (IA).

- En caso de un acceso venoso yugular interno destinado a hemodiálisis se sugiere la tunelización si se estima su permanencia superior a tres semanas (IA).

\section{¿Existen diferencias objetivas y significativas en la tasa de infecciones al considerar el sitio ana- tómico de inserción de un CVC convencional?}

Existen pocos estudios comparativos randomizados que hayan explorado específicamente diferencias en la tasa de bacteriemias asociadas a diferentes sitios de inserción de CVC. Estos estudios no han incluido hasta ahora comparaciones controladas entre accesos venosos yugulares internos versus subclavios.

Revisiones de un número limitado de trabajos no controlados dan cuentan de una ausencia de diferencias en las tasas de bacteriemias entre estas dos vías, aunque con una mayor frecuencia de punciones arteriales pero menos frecuencia de un mal posicionamiento para el acesso yugular.
Ambos abordajes no difirien en la frecuencia de hemotórax o neumotórax ${ }^{39}$.

El acceso femoral en pacientes adultos en unidades críticas ha demostrado un mayor porcentaje de complicaciones infecciosas y trombosis en comparación a un acceso subclavio ${ }^{40}$.

El acceso subclavio para hemodiálisis se ha asociado a estenosis significativa u oclusión completa de la vena subclavia por trombosis en comparación al acceso por vía yugular interna. Este fenómeno impide contar con una fístula arteriovenosa a futuro en la extremidad ipsilateral y hace recomendable evitar esta vía para estos propósitos $^{41}$.

Las diferencias en las tasas de infecciones o complicaciones trombóticas no han sido observadas o reportadas en pacientes pediátricos y por ello estos resultados no pueden ser extrapolados a esta población.

\section{Recomendaciones:}

- La elección del sitio anatómico de inserción de un CVC convencional depende de la experiencia y confiabilidad del equipo con un sitio en particular, de la duración estimada de uso y de factores anatómicos de cada paciente (IIB).

- No existe una evidencia sustantiva que señale una mayor frecuencia de complicaciones infecciosas en la inserción de un CVC convencional en la vena yugular interna en comparación a un abordaje subclavio en pacientes adultos (IIB).

- No se recomienda la instalación preferencial de un CVC por vía femoral en pacientes adultos debido a su mayor frecuencia de complicaciones infecciosas y mecánicas (IA).

- No hay estudios comparativos sobre diferencias de tasas de complicaciones infecciosas de acuerdo al sitio anatómico de la inserción, en pacientes pediátricos. La evidencia disponible no señala una mayor tasa de complicaciones infecciosas o trombóticas asociada al acceso femoral en pacientes pediátricos: No se puede establecer una contraindicación para utilizar esta vía en pacientes pediátricos. Sin embargo, se deben considerar algunos factores del huésped tales como la incontinencia urinaria o fecal, que pudieran favorecer la infección (IIB).

- No se debe utilizar el acceso subclavio para instalar CVC destinados a hemodiálisis (IIA).

\footnotetext{
¿Debemos utilizar catéteres vasculares impregnados o cubiertos con algún antimicrobiano y/o antiséptico para optimizar la prevención de ITS asociadas? ¿Se benefician algunos grupos específicos con esta estrategia?
} 


\section{¿Es una estrategia costo-efectiva?}

El fundamento de esta estrategia es disminuir la colonización por diferentes microorganismos ya sea en la parte exoluminal o endoluminal del catéter vascular. Para ello se encuentran disponibles diferentes modalidades de catéteres vasculares. Los compuestos utilizados incluyen cefazolina, minociclina, rifampicina, clorhexidinasulfadiazina o un mango de plata (silver cuff). Algunos de ellos han sido diseñados combinando compuestos.

Los estudios iniciales fueron desarrollados agregando un antimicrobiano por inmersión (antibiotic coating) al catéter ya elaborado, una estrategia asociada a una pérdida del compuesto desde el catéter ${ }^{3}$. La elusión precoz del antimicrobiano ha sido controlada aplicando un compuesto surfactante catiónico que facilita la unión de compuestos aniónicos (antimicrobianos). Este proceso se conoce como unión del antimicrobiano (antibiotic bonding) Finalmente, los compuestos antimicrobianos pueden ser incorporados en el proceso de síntesis del CVC, aspecto que se conoce como impregnación ${ }^{3}$. Los CVCs con un cuff o balón de plata (silver cuff) representan una variante de esta estrategia donde sólo un segmento del catéter en posición subcutánea contiene un compuesto antimicrobiano, en este caso un antiséptico.

Para el caso de los CVCs con manguito o cuff de plata, sólo uno de cuatro estudios controlados ha logrado demostrar un efecto favorable sobre las tasas de bacteriemias asociadas a $\mathrm{CVCs}^{3}$. De la misma manera, un estudio con CVCs cubiertos con cefazolina no pudo demostrar un impacto favorable para mejorar la prevención de complicaciones infecciosas ${ }^{42}$.

Sólo uno de varios estudios y un meta-análisis han demostrado que la utilización de catéteres impregnados con clorhexidina-sulfadiazina reduce significativamente la tasa de infecciones asociadas a catéteres vasculares incluyendo episodios de bacteriemias $^{43-45}$. Los CVCs involucrados en estos estudios han sido de tipo transitorio en pacientes quirúrgicos, inmunocomprometidos y han incluido catéteres con clorhexidina-sulfadiazina, minociclina-rifampicina y cefazolina ${ }^{43-46}$. En el meta-análisis reportado se omitió un trabajo comparativo entre clorhexidina-sulfadiazina y CVCs convencionales que contiene el mayor número de pacientes evaluados en este tipo de estudios y que no encontró diferencias significativas ${ }^{3}$. En este último trabajo los pacientes eran portadores de enfermedades oncohematológicas ${ }^{47}$.

Al menos un estudio ha comparado catéteres impregnados con clorhexidina-sulfadiazina ver- sus CVCs cubiertos con minociclina-rifampicina utilizando $\mathrm{TDMAC}^{48}$, habiéndose demostrado mayor eficacia para este último tipo de catéteres.

Para catéteres impregnados con clorhexidinasulfadiazina se ha demostrado un ahorro económico en comparación al uso de catéteres no impregnados, convirtiendo a este enfoque en una estrategia costo-efectiva ${ }^{49}$.

Los estudios con uso de catéteres cubiertos o impregnados en pacientes pediátricos son escasos y existe referencia a un trabajo presentado en una Conferencia APIC (Association for Professionals in Infection Control) que compara tasas de bacteriemia de catéteres impregnados con minociclina-rifampicina versus catéteres cubiertos con heparina en 183 pacientes, y que muestra una disminución de bacteriemia de 8,6/1.000 días catéter a 6,2/1.000 aunque sin lograr significación estadística ${ }^{50}$.

Por otra parte, la minociclina ha sido descrita asociada a enfermedad del suero en adolescentes que toman el medicamento por un período prolongado (10 a 30 días) ${ }^{51}$ y aún más, el uso tópico de clorhexidina se ha asociado a reacciones adversas en el recién nacido tales como dermatitis de contacto y bradicardia ${ }^{52}$. Por estas razones no se recomienda el uso de CVCs impregnados o cubiertos con minociclina o clorhexidina en pacientes RN o lactantes ${ }^{53}$.

\section{Recomendaciones:}

- La utilización de CVCs impregnados con antisépticos y antimicrobianos puede disminuir el riesgo de infecciones asociadas a estos catéteres en pacientes adultos con CVC de uso transitorio y permite ahorrar recursos económicos a pesar de su mayor costo de adquisición. Sin embargo, no se recomienda su uso como una herramienta básica de prevención debido a que la evidencia sobre su eficacia es aún limitada y a la falsa sensación de seguridad que puede generar su aplicación, en desmedro de otras medidas efectivas y básicas de prevención (IA).

- Su uso puede ser considerado en aquellas situaciones epidemiológicas donde las tasas persisten elevadas a pesar de los mejores esfuerzos de control (IA).

- La utilización de estos catéteres en pacientes adultos con enfermedades oncohematológicas no ha demostrado un efecto beneficioso y en ellos su uso no se recomienda (IA).

- La aplicación de esta tecnología en pacientes pediátricos no ha sido adecuadamente evaluada (IIB).

\section{¿Aumenta el número de lúmenes del CVC el riesgo de complicaciones infecciosas?}

Algunos estudios sugieren que el uso de caté- 
teres de múltiple lumen comparado con un solo lumen tiene un mayor riesgo de infección ${ }^{54,55}$. Sin embargo, en un estudio randomizado y controlado en pacientes con NPT seguidos por un periodo de 24 meses, que comparó CVCs de doble y triple lumen, no se encontró una diferencia significativa en la incidencia de infección asociada a catéter $(2 \%$ en catéteres de doble lumen versus $1,9 \%$ en los de triple lumen $)^{56}$. Los autores señalan que el uso de CVCs de tres lúmenes parece ser seguro y la incidencia de infección está relacionada al manejo por un equipo dedicado a NTP con adherencia estricta a las recomendaciones ${ }^{56}$. En otro estudio randomizado y controlado, comparando catéteres de doble lumen con un solo lumen en 112 pacientes con NPT, no se encontró infección asociada a catéter en ninguno de los 2 grupos, por lo que se concluye que el uso de doble lumen es tan seguro como el de un solo lumen, siguiendo protocolos de manejo y seguimiento estricto ${ }^{57}$.

En CVCs no destinados a NPT, tampoco se han observado diferencias significativas en las infecciones o sepsis relacionada a catéter, tal como lo demuestra un estudio randomizado desarrollado con pacientes críticos, comparando catéteres de un lumen versus catéteres de doble lumen $^{58}$. En otro ensayo randomizado con pacientes adultos quirúrgicos que comparó catéteres de un lumen versus triple lumen, tampoco se encontraron diferencias en la incidencia de infecciones y además se demuestra que los de triple lumen permiten disminuir la necesidad de accesos periféricos ${ }^{59}$. Estudios en pacientes traumatológicos tampoco han demostrado diferencias significativas en las tasas de infección al comparar catéteres de un lumen versus triple lumen ${ }^{60}$. Estos resultados contrastan con aquellos obtenidos por estudios retrospectivos, por ejemplo en pacientes oncológicos, con catéteres tunelizados donde se observó una mayor frecuencia de infecciones asociada al catéter de doble lumen en comparación a los de un lumen ${ }^{61}$.

Recomendaciones:

- El número de lúmenes del CVC está dictado por las necesidades del paciente. El riesgo de infección o colonización aumenta con el grado de manipulación de las conexiones y no necesariamente, como lo han demostrado diferentes estudios, por el número de lúmenes del CVC. Por ello lo más importante, es la cuidadosa manipulación de las conexiones adhiriendo a las recomendaciones establecidas (IA).

- No se puede establecer una recomendación limitando el número de lúmenes del CVC ya que ello no contribuye a disminuir la frecuen- cia de bacteremias asociadas a CVCs, siempre y cuando se cumplan las medidas de prevención en su manipulación (IE).

\section{¿Es posible plantear una inmunización activa contra S. aureus, uno de los agentes más importantes de bacteremia o sepsis asociada a CVC?}

S. aureus se divide en 12 serotipos según su polisacárido capsular. Esta estructura, al igual que lo observado en otras cocáceas Gram positivas, actúa como factor de virulencia o patogenicidad que facilita la invasión al inhibir la fagocitosis. Los serotipos 5 y 8 de $S$. aureus explican el 80 a $90 \%$ de las infecciones causadas por este agente y el serotipo 336 explica la casi totalidad del 15\% restante. Este polisacárido es un pobre inmunógeno por lo que debe conjugarse a una proteína transportadora para lograr inmunogenicidad. Los polisacáridos 5 y 8 se han asociado a la exoproteína A recombinante de Pseudomonas aeruginosa, en forma de toxoide, para ser administrados como vacuna. Esta presentación ha resultado ser inmunogénica y bien tolerada en adultos humanos voluntarios. Esta vacuna bivalente ha sido evaluada en un estudio de fase III en pacientes con insuficiencia renal crónica terminal en hemodiálisis y portadores de fístula arteriovenosa. El estudio doble ciego randomizado incluyó 1.800 pacientes que se dividieron en 2 grupos: uno placebo y otro que recibió una dosis de vacuna; ambos fueron seguidos durante un período de 40 semanas $^{62}$. La vacuna fue bien tolerada, con pocos efectos adversos y al término de las 40 semanas se demostró una reducción significativa de bacteriemia por S. aureus $(57 \%, \mathrm{p}=0,015)$. Si bien estos trabajos son promisorios, se requiere esperar la evidencia de la eficacia de esta vacuna en pacientes críticos en quienes se instaló un CVC.

\section{¿Debemos utilizar ultrasonido al instalar el CVC?}

Pocos estudios han logrado demostrar una ventaja en la utilización del ultrasonido para apoyar la instalación de CVC en posición yugular interna o subclavia ${ }^{63}$. No obstante, un meta-análisis logró demostrar una ventaja para disminuir las complicaciones mecánicas (punción arterial, neumotórax, etc.), intentos fallidos, intentos de punción y mal posicionamiento ${ }^{63}$. Estos estudios no han evaluado hasta ahora la importancia del ultrasonido para disminuir la tasa de infecciones asociadas a CVC y por otra parte, el uso de esta estrategia encarece considerablemente los costos y obliga al uso de recursos humanos escasamente disponibles en nuestro medio las 24 horas del día. Por ahora, la relevancia e impacto del ultra- 
sonido en la prevención de infecciones asociadas a CVC requiere de estudios específicos dirigidos a evaluar este aspecto ${ }^{63}$.

Recomendación:

- No se recomienda la instalación de CVC bajo apoyo con ultrasonido de rutina (DI).

\section{Intervenciones para prevenir infecciones durante la instalación de CVC}

\section{¿Dónde se debe instalar el CVC?}

No existen estudios comparativos directos que hayan evaluado este aspecto. Sin embargo, esta pregunta destaca la experiencia en la prevención de las infecciones asociadas a CVCs cuando grupos de trabajo entrenados se dedican a su instalación. Un estudio retrospectivo en 96 catéteres Hickman puesto en pabellón o en la pieza del paciente no demostró diferencias en términos de éxito del procedimiento o complicaciones ${ }^{64}$. Sin embargo, varios estudios demuestran una disminución importante de los costos al instalar estos catéteres en la pieza del paciente ${ }^{64-66}$. Los CVCs pueden ser instalados en cualquier lugar donde se asegura la comodidad necesaria para el operador y sus asistentes durante el proceso de instalación y donde exista una infraestructura adecuada para ello.

Recomendaciones:

- Los CVCs pueden ser instalados en cualquier lugar hospitalario que asegure comodidad para el operador y sus asistentes durante el proceso de instalación y que tenga la infraestructura adecuada (IIB).

- En la instalación del CVC tiene mayor relevancia el entrenamiento del operador (IA).

\section{¿Cuáles son las barreras que deberían ser utilizadas en la instalación de un CVC para prevenir las infecciones asociadas?}

En un estudio randomizado controlado se comparó un grupo donde el operador utilizaba gorro y mascarilla no estéril, delantal y guantes estériles con el paciente casi totalmente cubierto con un campo estéril, contra otro grupo, donde el operador sólo utilizaba guantes estériles y el paciente fue cubierto por un campo estéril menor. La piel del paciente fue preparada en ambos casos, inicialmente con alcohol y luego con povidona yodada, con un tiempo de espera de al menos 2 minutos. El estudio incluyó CVCs por vía subclavia y CVCs insertados por vía periférica. La tasa de bacteriemia fue 6 veces superior en el grupo con barreras menores y las medidas máximas fueron además costo-beneficio favorables ${ }^{67}$. Estos ante- cedentes respaldan el concepto de instalación con las máximas barreras de protección posibles durante la instalación.

Recomendación:

- Se debe asegurar la instalación de cualquier CVC utilizando las máximas barreras de protección para impedir la contaminación del campo estéril. La instalación debe incluir el uso en el operador de mascarilla y un gorro no estéril, delantal estéril, guantes estériles y un campo estéril lo más amplio posible. La piel del paciente debe ser preparada con un antiséptico y el operador debe lavarse las manos con jabón antiséptico antes de utilizar los guantes estériles (IA).

\section{¿Existen diferencias objetivas para prevenir infecciones asociadas a CVC según el tipo de antiséptico con el que se prepara la piel del paciente?}

El uso de antisépticos en la preparación de la piel antes de la inserción de un CVC disminuye la infección el riesgo de infección asociado a catéter. La povidona yodada ha sido la solución más utilizada. Sin embargo, se han publicado al menos 8 trabajos randomizados y controlados, en los que se compara el uso de povidona con clorhexidina. Un meta-análisis logró demostrar una reducción significativa en los episodios de bacteriemia al utilizar clorhexidina en lugar de povidona yodada ${ }^{68}$. El efecto protector no parece ser modificado por diferentes concentraciones de clorhexidina en base alcohólica $(0,5$ a $1 \%)$ o solución acuosa al $2 \%$. La povidona yodada es el antiséptico de elección en la preparación del paciente para hemodiálisis debido a la evidencia publicada sobre su eficacia protectora en comparación a placebo ${ }^{69,70}$.

Recomendaciones:

- Se debe utilizar antiséptico en la preparación de la piel del paciente antes de la instalación del CVC(IA).

- Se deben respetar los tiempos de espera al aplicar un antiséptico específico para lograr su máximo efecto antes de la instalación (3 minutos para clorhexidina, 90 segundos para povidona yodada y evaporación en caso de soluciones con alcohol).

- Cuando sea posible y no esté contraindicado, se debe preferir la utilización de una solución con clorhexidina sobre povidona yodada para efectuar antisepsia de la piel (IA).

- En casos de CVCs destinados a hemodiálisis se debe preferir el uso de povidona como antiséptico en la preparación de la piel (IA).

- No se recomienda la utilización de clorhexidina 
en neonatos de muy bajo peso $(<1.000 \mathrm{~g})$ o en lactantes con una edad gestacional $<26$ semanas durante los primeros días después del parto, por el alto riesgo de dermatitis de contacto $^{2,71}$. Recomendaciones internacionales han extendido la ventana de tiempo a los 2 meses de vida (IA).

- Las concentraciones evaluadas y efectivas de clorhexidina en la prevención de bacteriemias por CVCs, ya sea por estudios individuales o meta-análisis, corresponden a soluciones acuosas al $2 \%$ o soluciones en base alcohólica del 0,5 ó $1 \%$.

\section{¿Existe un número máximo de venopunciones en la instalación del CVC?}

Un mayor número de punciones implica mayor dificultad durante el procedimiento, lo que puede aumentar las complicaciones mecánicas. Un estudio reciente, prospectivo y randomizado, comparando las complicaciones de las punciones femoral y subclavia mostró que la duración de la inserción del catéter se asociaba a una mayor incidencia de complicaciones mecánicas, pero no de ITS $^{40}$. En otro estudio observacional sobre punción subclavia, el número de punciones se asoció a mayor incidencia de neumotórax o falla en el procedimiento de instalación, sin hacer mención a las complicaciones infecciosas ${ }^{72}$. La mayor dificultad en el procedimiento no necesariamente aumenta el riesgo de ITS, no existiendo a la fecha estudios clínicos que investiguen directamente esta pregunta.

\section{¿Existen diferencias significativas entre diferentes sistemas de protección del sitio de inserción?}

El material de protección para el sitio de inserción de CVC ha sido materia de controversia en las últimas décadas. En un principio, el sitio de inserción de los catéteres, era protegidos con gasa y tela adhesiva. Posteriormente, en la década del 60, aparecieron apósitos transparentes hechos de una delgada película de poliuretano. El uso de estos apósitos se hizo muy popular debido a que permiten la inspección visual del sitio de inserción junto con proveer un cierre oclusivo que contribuye también a la fijación del catéter. Posteriormente, hubo estudios que demostraron que el uso de apósitos transparentes podía estar relacionado al aumento de bacteriemias asociadas a CVC. El mecanismo se ha atribuido a la colonización bacteriana en el sitio de inserción que puede estar aumentada por la humedad que se produce bajo el apósito transparente por falta de permeabilidad o por cambios menos frecuen- tes $^{73,74}$. Después de los primeros estudios, los fabricantes de apósitos transparentes han ido modificando su diseño con el fin de aumentar la permeabilidad.

Riesgos de bacteriemia asociados a material de protección del sitio de inserción. En 1993, se realizó un meta-análisis donde se analizaron 15 estudios publicados entre 1966 y 1991 que comparaban el riesgo de bacteriemia y colonización del catéter o sitio de inserción entre pacientes que usaban como protección apósitos transparentes o gasa seca. Los criterios de inclusión fueron ensayos clínicos randomizados en pacientes hospitalizados. Se seleccionaron 7 de los 15 estudios. Los resultados de este meta-análisis indicaron diferencias significativas en los riesgos de colonización y una tendencia hacia una mayor frecuencia de bacteriemia en el grupo que usó apósitos transparentes ${ }^{73}$. Posteriormente, en 1996 se realizó una revisión con el fin de analizar nuevamente el estado de la investigación en la materia. En esa oportunidad se analizaron en forma no sistemática estudios realizados antes del año 1990 y también en años posteriores. En el periodo previo hubo estudios que mostraron diferencias en las tasas de bacteriemia y estudios que no las mostraron. Posterior a 1990, todos los estudios que compararon apósitos transparentes de distintos diseños (mayor o menor permeabilidad) o apósitos transparentes con gasa seca, no mostraron diferencias en las tasas de bacteriemia. La conclusión de los autores de esta revisión fue que la diferencia entre apósitos transparentes y gasa seca en términos de riesgo de bacteriemia continúa siendo un tema controvertido y que los resultados de los estudios son contradictorios y en algunas ocasiones difíciles de interpretar por lo que la pregunta que si los apósitos transparentes constituyen un mayor riesgo no está respon$\mathrm{dida}^{74}$. De cinco ensayos clínicos randomizados publicados entre 1986 y 1994, en uno hubo diferencias significativas en riesgos de bacteriemia ${ }^{75}$ y en cuatro no hubo diferencias ${ }^{76-79}$. Entre 1997 y 2001 se han realizado dos ensayos clínicos randomizados donde se compararon distintas tecnologías de apósitos transparentes ${ }^{80,81}$ y un ensayo clínico randomizado para evaluar las ventajas del uso de un apósito transparente con un parche de clorhexidina frente a apósitos transparentes convencionales ${ }^{71}$. En ninguno de estos estudios se encontraron diferencias en las tasas de bacteriemia.

Recomendaciones:

- Se debe proteger el sitio de inserción de CVC con un apósito estéril (IA).

- En la protección del sitio de inserción se puede 
utilizar un apósito transparente semi-permeable, permeable o gasa seca (IB).

- Se debe cambiar el sistema de protección si éste está mojado o sucio (IB).

- La frecuencia de curaciones del sitio de inserción debe realizarse de acuerdo a la evaluación local (No resuelto).

- No existe evidencia suficiente que apoye el uso de apósitos con clorhexidina para prevenir riesgos de bacteriemia (No resuelto).

\section{Intervenciones para prevenir infecciones en el manejo de CVC}

\section{¿Con qué frecuencia deberían ser cambiados los CVC para prevenir infecciones? ¿Representa el recambio por la técnica de Seldinger un mayor riesgo de infección?}

El cambio rutinario de catéteres centrales no se recomienda debido a la evidencia aportada por diferentes estudios controlados que no demuestran una disminución del riesgo de infección al comparar un reemplazo con esquemas prefijados cada 3 ó 7 días en comparación con un recambio dictado según las necesidades y evolución del paciente $^{82,83}$. Esta situación ha sido demostrada también en forma independiente para catéteres pulmonares y catéteres de hemodiálisis ${ }^{84,85}$.

Un meta-análisis desarrollado para contestar la interrogante sobre el riesgo (o ventaja) del recambio por técnica de Seldinger para desarrollar infección del sitio de entrada o bacteriemia, demostró una tendencia desfavorable del recambio por una guía de alambre para estos parámetros en comparación a una punción en un nuevo sitio de punción, aunque sin alcanzar significación estadística (RR 1,52 IC 95\% 0,34-6,73 para infección del sitio de entrada; RR 1,72 IC 95\% 0,89-3,33 para bacteriemia asociada a CVC, respectivamente $)^{82}$. Por el contrario, hubo una tendencia hacia una menor frecuencia de complicaciones mecánicas al efectuar un recambio por la técnica de Seldinger (RR 0,51 IC 95\% 0,2-1,32). Los autores del meta-análisis señalan que el tema aún no puede ser resuelto y se requieren más estudios comparativos con este propósito.

Recomendaciones:

- No se recomienda el cambio rutinario de un CVC a plazos prestablecidos (IA).

- El recambio por técnica de Seldinger se puede efectuar en caso de que no exista infección del sitio de entrada del catéter (IB). Sin embargo, debido a que no se recomienda el reemplazo rutinario de CVC, su aplicación queda restringida a situaciones aisladas.
- No efectuar recambio de un CVC por la técnica de Seldinger si existe infección del sitio de entrada o bacteriemia asociada al catéter en esa posición (IA).

\section{¿Tiene utilidad el uso de heparina en la prevención de infecciones asociadas a CVC?}

El depósito de fibrina y la formación de trombos en la superficie del catéter ocurre en las primeras horas de instalación, encontrándose en 35 a $67 \%$ de los catéteres de largo uso. Se ha demostrado una asociación entre la formación de trombo y el desarrollo de embolia pulmonar, trombosis séptica e infección asociada a catéter $^{86}$. La heparina ha sido usada como una estrategia de prevención de trombos y mantención de la permeabilidad del lumen.

En un meta-análisis de 12 trabajos randomizados y controlados publicado en 1998, en que se evalúa el uso de heparina profiláctica en pacientes con catéteres de corta duración, se encontró una disminución en el riesgo de trombosis venosa central (riesgo relativo de 0,43 , IC $95 \%$ 0,23-0,78) y una disminución de la colonización del catéter con un RR de 0,18 (IC 95\% 0,06$0,60)$. Se observó también una tendencia favorable en el riesgo de bacteriemia asociada a CVC con un RR de 0,26 pero un amplio intervalo de confianza (IC 95\% 0,02-1,03). Los autores señalan que los criterios para definir bacteriemia asociada a catéter no fueron exigentes como los actualmente en uso, debido a la antigüedad de los estudios originales y que por lo tanto, el efecto beneficioso sobre la prevención de bacteriemias requiere de mayores estudios.

$\mathrm{Al}$ analizar por separado los catéteres de arteria pulmonar recubiertos con heparina, también se demostró una disminución de la formación de trombosis, especialmente en las primeras 24 horas de instalación con un RR de 0,08, IC 95\% $0,02-0,37^{87}$.

Los esquemas de heparina utilizados en estos trabajos han sido variables y han incluido heparina en la solución de alimentación parenteral total (3 $\mathrm{U} / \mathrm{mL}$ ), 5.000 u cada 6 ó 12 h como instilación por el CVC, heparina de bajo peso molecular en una dosis de $2.500 \mathrm{U}$ una vez al día o un catéter impregnado con este compuesto en uno de los estudios. Por otra parte, la mayor parte de estos ensayos se han realizado en pacientes de cuidados intensivos adultos y sólo en un estudio de pacientes pediátricos oncológicos ${ }^{87}$.

La mejor estrategia de prevenir el riesgo de trombosis no ha sido delineada aún debido al riesgo potencial de trombocitopenia autoinmune asociado al uso prolongado de heparina conven- 
cional y al mayor costo de las heparinas de bajo peso molecular que tienen menor riesgo de trombocitopenia. Los anticoagulantes, como la warfarina en bajas dosis, disminuyen el riesgo de trombosis pero se asocian a un aumento del tiempo de protrombina ${ }^{88,89}$.

Recomendaciones:

- El uso de heparina en catéteres de corta duración disminuye el riesgo de trombosis venosa central y podría disminuir el riesgo de bacteriemia y sepsis asociada a catéteres venosos centrales. Sin embargo, los estudios desarrollados no han logrado demostrar claramente un efecto en la prevención de bacteriemias asociadas a CVC. No es una estrategia recomendada para prevenir infecciones (IIB); sin embargo, puede ser adoptada a nivel local para disminuir el riesgo de trombosis y prolongar la duración del CVC (IA).

- Su utilización puede desencadenar trombocitopenia. Su uso en pacientes pediátricos no ha sido debidamente evaluado.

\section{¿Tiene utilidad la profilaxis local o sistémica con antimicrobianos para prevenir las infec- ciones asociadas a catéteres venosos centrales?}

Diferentes estrategias han sido exploradas en este rubro con el propósito de disminuir la tasa de complicaciones infecciosas asociadas al cateterismo venoso central (Tabla 2). Se han agrupado arbitrariamente estas intervenciones en profilaxis sistémica, profilaxis tópica, instilación con antimicrobianos y finalmente intervenciones específicas para pacientes en hemodiálisis.

Profilaxis con antimicrobianos sistémicos en CVC convencionales. Estudios con vancomicina o teicoplanina utilizados en forma profiláctica no han demostrado eficacia para disminuir las infecciones asociadas a CVC en pacientes adul$\operatorname{tos}^{90}$. En contraste, esta estrategia ha demostrado ser efectiva para disminuir las tasas de bacteriemia en neonatos prematuros que reciben nutrición parenteral, aunque no han tenido impacto sobre

Tabla 2. Intervenciones profilácticas con antimicrobianos en cateterismo venoso central

- Profilaxis sistémica con antimicrobianos para CVC convencionales.

- Profilaxis tópica con antimicrobianos (mupirocina) en CVC convencionales.

- Instilación profiláctica de antimicrobianos en el CVC (lock prophylaxis).

- Intervenciones profilácticas tópicas o sistémicas en pacientes con catéter de hemodiálisis. las tasas de mortalidad ${ }^{2,90-92}$.

A pesar de esta ventaja sobre la morbilidad de las bacteriemias asociadas al cateterismo venoso central en un grupo seleccionado de pacientes, existe un amplio consenso para no utilizar vancomicina profiláctica por el gran riesgo de presión selectiva sobre cepas de enterococo resistente a vancomicina $u$ otras especies Gram positivas en general.

Otros antimicrobianos utlizados como profilaxis también han logrado demostrar un efecto positivo en la disminución de los episodios de bacteriemia asociada a CVC o infección del sitio de entrada, por ejemplo al utilizar rifampicina y novobiocina oral en forma prolongada (> 30 días), aunque más de un tercio de los pacientes oncológicos que recibieron este esquema no toleró la profilaxis ${ }^{93}$.

Profilaxis con mupirocina en el sitio de inserción de CVC convencionales. Estudios comparativos efectuados con mupirocina versus antisepsis estándar han demostrado una reducción en la colonización del extremo distal del catéter en pacientes con cateterismo vascular por corto tiempo pero no han estudiado específicamente una reducción en las tasas de bacteremias ${ }^{94}$. Los ensayos realizados en pacientes en hemodiálisis con mupirocina, en los que sí se ha demostrado un efecto protector, no pueden ser extrapolados fácilmente debido a diferencias en la permanencia del cateterismo vascular y en las tasas de portación nasal de S. aureus ${ }^{95}$. La aplicación prolongada de mupirocina se ha asociado a emergencia de cepas resistentes de Staphylococcus $^{96,97}$.

Profilaxis con instilación de antimicrobianos (lock prophylaxis). Esta estrategia ha utilizado una instilación o baño de vancomicina u otros compuestos para disminuir el riesgo de bacteriemias asociadas a CVC de uso prolongado. Esta intervención ha sido evaluada especialmente para catéteres tunelizados en pacientes pediátricos oncológicos y comparada contra el uso de baños de heparina en forma aislada ${ }^{98}$. Diferentes estudios han obtenido resultados discordantes sobre la eficacia de esta intervención para reducir las bacteremias asociadas a CVCs tunelizados en este tipo de pacientes ${ }^{98-100}$.

Esta estrategia también ha sido analizada en pacientes adultos neutropénicos con CVCs no tunelizados logrando demostrar su eficacia para disminuir bacteriemias asociadas a CVCs. La instilación con vancomicina se efectuó sólo durante el período de neutropenia ${ }^{101}$. 
A pesar de estos logros, la aplicación rutinaria de una profilaxis con vancomicina en instilación, es resistida globalmente por el riesgo de incorporar una gran presión selectiva sobre cocáceas Gram positivas y favorecer la emergencia de cepas de enterococos o estafilococos resistentes a vancomicina.

Intervenciones profilácticas tópicas o sistémicas en pacientes con catéter de hemodiálisis.

Diferentes estrategias han sido estudiadas con este propósito en pacientes sometidos a hemodiálisis mediante CVC. Las intervenciones profilácticas incluyen el uso tópico de mupirocina en el sitio de inserción del catéter; el uso de este mismo compuesto para controlar la portación nasal de $S$. aureus en el paciente; el uso de diferentes antimicrobianos sistémicos como profilaxis antes de la inserción y la instilación o baño de algún antimicrobiano en el lumen del catéter.

- Uso profiláctico tópico nasal con mupirocina en pacientes sometidos a hemodiálisis. La aplicación tópica nasal de mupirocina demostró en un estudio doble ciego randomizado, ser de utilidad contra placebo para disminuir la portación nasal de $S$. aureus en pacientes y disminuir la frecuencia de infecciones por este agente $^{102}$. Sin embargo, el trabajo citado involucró una serie muy pequeña de pacientes, tuvo una pérdida excesiva de pacientes asignados al grupo intervención e incluyó infecciones no asociadas al uso de un CVC en el grupo control ${ }^{102}$

- Uso profiláctico tópico con mupirocina en el sitio de inserción en pacientes sometidos a hemodiálisis. Sesso et $\mathrm{al}^{95}$ demostraron en un trabajo randomizado que el uso de mupirocina tópica en el sitio de inserción de un CVC para hemodiálisis reduce significativamente las infecciones del sitio de salida, los episodios de bacteriemia y además prolonga la vida útil del CVC destinado a hemodiálisis. A pesar de estos antecedentes, esta estrategia es ampliamente debatida debido a los reportes sobre la rápida emergencia de resistencia a mupirocina a los pocos meses de su introducción, al efecto dañino de este compuesto sobre el catéter de poliuretano y a la falsa sensación de seguridad al practicar esta intervención en desmedro de las medidas básicas de prevención de bacteriemias asociadas al cateterismo venoso central.

- Instalación del catéter de hemodiálisis con gentamicina u otros antimicrobianos. Esta estrategia utiliza soluciones de algún antimicrobiano para llenar el espacio muerto del
CVC al finalizar cada sesión de diálisis. Se ha explorado esta estrategia mediante baños de gentamicina usando como anticoagulante citrato. En un estudio randomizado comparado contra heparina en pacientes en hemodiálisis con catéteres tunelizados ${ }^{103}$, los autores lograron demostrar una reducción significativa e importante en las tasas de infección global y una prolongación en la vida útil del catéter. Sin embargo, los niveles plasmáticos de gentamicina determinados antes de cada sesión de diálisis se encontraban en un rango tóxico para una fracción de los pacientes que recibieron este compuesto y algunos de ellos manifestaron síntomas asociados. La concentración del baño fue de $40 \mathrm{mg} / \mathrm{ml}$ y se utilizaron 2 $\mathrm{ml}$ de esta solución por paciente.

\section{Recomendaciones globales sobre profilaxis} antimicrobiana en pacientes con CVC, incluyendo catéteres de hemodiálisis.

- La evidencia a favor de un efecto protector con profilaxis antimicrobiana sólo se ha obtenido en algunos de los numerosos estudios realizados utilizando diferentes estrategias de intervención. Existe amplio consenso para no respaldar su utilización en la prevención de las complicaciones infecciosas asociadas al cateterismo venoso central (IIE).

- Las razones para desaconsejar su uso están referidas a la falsa sensación de seguridad al aplicar estas estrategias en desmedro de las medidas más básicas de prevención, en la selección de microorganismos resistentes, en el posible daño de algunos compuestos al material del CVC y en el aumento innecesario de los costos de manejo de estos catéteres.

\section{¿Con qué frecuencia deben cambiarse los equipos de administración de fluidos?}

La mayor parte de las infecciones de torrente sanguíneo asociadas a catéteres intravasculares se relacionan con las cánulas insertadas, más que con la contaminación de los productos a infundir. Estas últimas han ocurrido en brotes epidémicos, lo cual llevó en la década de los 70 a recomendar el cambio rutinario de las vías venosas periféricas y los equipos de infusión cada 24 horas ${ }^{104}$. Posteriormente, gracias a la evidencia aportada por estudios randomizados, este período se ha extendido progresivamente a 48 horas $^{104-106}$ y luego a 72 horas ${ }^{107}$, aunque excluyendo de estas recomendaciones los equipos de infusión para administrar sangre, hiperalimentación, efectuar monitorización o extracción de muestras de sangre ${ }^{108,109}$. Los equipos de infusión 
que incluyen equipos de microgoteos, tampoco requieren ser cambiadas en un plazo menor a las 72 horas $^{110,111}$.

Que los plazos de recambio puedan ser prolongados en el futuro es posible ya que la evidencia aún está en desarrollo en esta área. Por ejemplo, en un estudio randomizado publicado recientemente, se demuestra la seguridad de los recambios cada 4 a 7 días para los equipos de infusión en pacientes con cáncer que no están recibiendo nutrición parenteral total, transfusiones sanguíneas o citoquinas ${ }^{112}$.

Los equipos de infusión para lípidos, nutrición parenteral o hemoderivados deben ser cambiados frecuentemente ( $\leq 24$ horas) debido a la evidencia que señala la participación de estos preparados como factor de riesgo de bacteriemias asociada a $\mathrm{CVC}^{2} \mathrm{y}$ al rápido crecimiento bacteriano o fúngico observado en condiciones experimentales luego de la contaminación inicial ${ }^{113-116}$.

Recomendaciones:

- Se recomienda el cambio rutinario de los equipos de infusión para CVC cada 72 horas (IA).

- Los equipos para administrar productos sanguíneos, NPT con lípidos o lípidos en forma aislada se deben cambiar cada 24 horas (IB).

\section{¿Tienen utilidad los sistemas de acceso sin aguja o con válvulas de reflujo para prevenir infecciones asociadas a CVC?}

En un esfuerzo por prevenir los accidentes cortopunzantes durante el procedimiento de terapia endovenosa se han diseñado diferentes dispositivos para proteger al personal de salud. Estos dispositivos incluyen, pero no están limitados a agujas con un escudo protector, equipos sin agujas con cánulas plásticas empotradas, equipos con una puerta de entrada tipo diafragma o tapa con una pre hendidura, con o sin válvulas de reflujo.

La evidencia recogida hasta ahora señala que estos equipos son útiles para prevenir accidentes cortopunzantes pero que no tienen impacto para disminuir las tasas de infecciones. Por ejemplo, en un trabajo prospectivo que incluyó 600 pacientes en 16 unidades excluyendo pacientes pediátricos, obstétricos, ginecológicos o críticos, se comparó un sistema de infusión endovenoso sin aguja y con válvula de reflujo contra un sistema convencional de cierre con heparina. Los autores concluyeron que este sistema muestra efectividad en reducir los accidentes por punción en el personal pero no demuestra diferencia alguna en las tasas de infecciones asociadas a los dispositivos ${ }^{117}$. Otro estudio más reciente que evaluó y comparó la contaminación y potencial riesgo de bacteriemia en un dispositivo con vál- vula de reflujo contra un sistema convencional, llegó a conclusiones similares ${ }^{118}$.

Un estudio in vitro comparó la frecuencia de contaminación de un sistema de infusión endovenoso sin aguja contra uno con aguja, expuestos experimentalmente a E. faecium $^{119}$. En la primera parte del experimento se puncionaron las puertas de entrada sin previa desinfección y en la segunda parte del experimento éstas se desinfectaron con alcohol al 70\%. Los resultados no demostraron diferencias significativas en la tasa de contaminación entre ambos sistemas cuando se cumple la norma de la desinfección antes de utilizar la puerta de entrada. Sin embargo, si no hay desinfección previa a la punción, puede ocurrir una alta tasa de contaminación. Un segundo trabajo de igual diseño comparó un sistema con y uno sin aguja llegando a las mismas conclusiones ${ }^{120}$. La introducción de estos sistemas en el ambiente hospitalario, sin una educación adecuada que refuerze el seguimiento de las instrucciones dadas por el fabricante, ha estado asociada a brotes de bacteriemias ${ }^{121}$.

\section{Recomendaciones:}

- Se deben desinfectar las puertas de entrada antes de acceder a los sistemas de infusión endovenosa (IA).

- Se recomienda cambiar los equipos de infusión sin agujas o con válvulas de reflujo junto con el resto de los elementos del set de administración cada 72 horas o bien, según las instrucciones del fabricante (IIB).

- Se debe asegurar que no existan roturas o filtraciones en el sistema de infusión endovenosa y se debe mantener el circuito sellado cuando no esté en uso (IB).

\section{Otros antecedentes}

Los temas revisados en las preguntas elaboradas no han incluido aspectos ya firmemente establecidos en la prevención de estas infecciones. Estas estrategias o temas validados incluyen algunos de los siguientes aspectos:

- Contar con un sistema de vigilancia epidemiológica activa para las infecciones asociadas a CVC con el propósito de conocer la frecuencia local de este problema. En Chile, se aplica un sistema definido por el Ministerio de Salud con 6 criterios posibles, 3 de ellos con respaldo microbiológico.

- Proteger el catéter pulmonar con una vaina externa que permita su movilización para no aumentar su contaminación durante los desplazamientos $^{122}$.

- No se debe aplicar éter o acetona en la limpieza inicial de la piel del paciente debido a que no 


\section{Tabla 3. Medidas básicas y fundamentales en la prevención de infecciones asociadas a CVCs}

- Desarrollar vigilancia activa de las bacteriemias asociadas a CVCs (en eventos por 1.000 días de exposición).

- Capacitar formalmente al personal de salud involucrado en la instalación o mantención del CVC.

- Adoptar una estrategia de diagnóstico microbiológico para reconocer las infecciones asociadas a CVCs en forma adecuada.

- Instalar el CVC bajo técnica aséptica: uso por parte del operador de mascarilla quirúrgica y gorro, lavado de manos con jabón antiséptico, delantal estéril y guantes estériles. El campo estéril debe ser lo más amplio posible.

- Aunque la elección del sitio de inserción de un CVC transitorio depende de varios factores que hacen más o menos conveniente un lugar sobre otro, se prefiere en general el acceso subclavio o yugular interno.

- Para pacientes que requieran terapias intermitentes y prolongadas, preferir un CVC tunelizado o un catéter permanente con bolsillo subcutáneo.

- Utilizar de preferencia un acceso por vía yugular interna para CVC destinados a hemodiálisis y utilizar un catéter tunelizado si se prevé que la duración de este acceso será > 3 semanas.

- Preparar la piel del paciente con antiséptico, respetando los tiempos mínimos de espera y efectuando un lavado previo con agua y jabón en la zona cuando ésta se aprecie sucia.

- Cubrir el sitio de punción con apósito estéril removiendo previamente materia orgánica o restos de sangre al final del proceso de instalación.

- Cambiar el apósito cada vez que se observe sucio, húmedo o contaminado.

- Efectuar la curación del sitio de inserción (cuando esté indicado o para exploración) con guantes (estériles o de procedimiento) y lavado de manos con jabón antiséptico antes del procedimiento.

- Efectuar el recambio de los equipos de infusión cada 72 horas para medicamentos, nutrición parenteral total sin lípidos o soluciones generales.

- Efectuar el recambio de los equipos de infusión involucrados en la administración de lípidos o hemoderivados cada 24 horas.

- Desinfectar los sitios de conexión con alcohol al 70\% antes de su utilización.

- Retirar el CVC cuando se termine la indicación para su uso.

Tabla 4. Medidas optativas que pueden ser consideradas en la prevención de infecciones asociadas a CVCs

\begin{tabular}{l}
\hline Intervención \\
\hline - Preferir CVC de poliuretano, silicona o teflón.
\end{tabular}

- Preferir clorhexidina en lugar de povidona como antiséptico para la preparación de la piel del paciente.

- Utilizar CVC impregnados con clorhexidinasulfadiazina o rifampicina-minociclina para cateterismos de corto plazo en aquellos casos donde a pesar de las medidas básicas no se logren reducir las tasas de infección.

- Utilizar heparina para prevenir infecciones asociadas y prolongar la duración de CVC.

- Optar por CVCs insertados periféricamente para simplificar la instalación de estos equipos.

\section{Comentarios}

Los catéteres de PVC, polietileno, nylon y polipropileno están asociados a mayor trombogenicidad y son más rígidos.

Efecto favorable demostrado. Se recomienda su uso cada vez que sea posible. Contraindicado por ahora en pacientes bajo 2 meses de vida.

Impacto favorable observado en algunos estudios con CVCs transitorios. No ha demostrado un efecto favorable en pacientes oncohematológicos.

No se ha demostrado su utilidad para prevenir infecciones pero disminuye los eventos trombóticos en forma significativa y mejora la sobrevida del catéter por este motivo.

No asociados a mayor frecuencia de complicaciones infecciosas. Pueden ser instalados por profesionales no médicos en la cama del paciente. Asociados a fallas de instalación o mal posicionamiento. 
disminuye la frecuencia de infecciones y además se asocia a efectos adversos locales como dolor o inflamación en forma significativa ${ }^{123}$.

- Manipulación con técnica aséptica del CVC, incluyendo lavado de manos y uso de guantes. El tipo de jabón (común o antiséptico) o guantes (estériles o de procedimiento) debe ser efectuado según las recomendaciones locales.

\section{Aspectos no cubiertos en este consenso}

Este consenso no ha revisado aspectos relativos al uso de catéteres umbilicales, arteriales u otros tipos de catéteres tales como el balón de contrapulsación aórtica o de procedimientos angiográficos.

\section{Tabla 5. Intervenciones no recomendadas en la} prevención de infecciones asociadas a CVCs

- Limpieza con éter o acetona de la piel del paciente antes de la inserción.

- Tunelización rutinaria de CVCs transitorios en posición subclavia en pacientes críticos.

- Destinar un CVC en posición subclavia para hemodiálisis

- CVC instalado en posición femoral en adultos como primera elección.

- CVCs cubiertos o impregnados con antimicrobianos como estrategia básica de prevención.

- Instalación del CVC en pabellón quirúrgico en forma rutinaria.

- Utilizar ultrasonido para orientar la instalación del CVC con el objetivo de disminuir las complicaciones infecciosas.

- Cambio rutinario del CVC a plazos preestablecidos.

- Profilaxis sistémica o tópica con antimicrobianos en forma rutinaria.

\section{Jerarquización de las recomendaciones y medidas básicas de prevención}

Las diferentes estrategias de prevención deben ser aplicadas en conocimiento de su peso o impacto para evitar las complicaciones infecciosas asociadas a los CVC. Esta sección del documento tiene por objeto establecer prioridades en estas estrategias y para ello se han dividido en medidas básicas y optativas. Además se señalan algunas intervenciones no recomendadas.

\section{Bibliografía}

1.- Otaíza F, Brenner P. Informe de vigilancia epidemiológica de las infecciones intrahospitalarias 19992000. Ministerio de Salud, Chile.

2.- Centers for Disease Control and Prevention. Guidelines for the prevention of intravascular catheter-related infection. MMWR 2002; 51 RR-10: 1-36.

3.- Pai M P, Pendland S L, Danzinger L H. Antimicrobialcoated/bonded and-impregnated intravascular catheters. Ann Pharmacother 2001; 35: 1255-63.

4.- Pascual A. Pathogenesis of catheter-related infections: lessons from new designs. Clin Microbiol Infect 2002; 8: 256-64.

5.- Sherertz R J, Ely E W, Westbrook D M et al. Education of physicians-in-training can decrease the risk for vascular catheter infection. Ann Intern Med 2000; 132: 641-8.

6.- Eggimann P, Harbarth S, Constantin M N, Touveneau $\mathrm{S}$, Chevrolet J C, Pittet D. Impact of a prevention strategy targeted at vascular-access care on incidence of infections acquired in intensive care. Lancet 2000; 355: $1864-8$

7.- Tomford J W, Hershey C O. The i.v. therapy team: impact on patient care and costs of hospitalization. NITA 1985; 8: 387-9.

8.- Soifer N E, Borzak S, Edlin B R, Weinstein R A. Prevention of peripheral venous catheter complications with an intravenous therapy team: a randomized controlled trial. Arch Intern Med 1998; 158: $473-7$.

9.- Davis D, O'Brien M A, Freemantle N, Wolf F M, Mazmanian P, Taylor-Vaisey A. Impact of formal continuing medical education: do conferences, workshops, rounds, and other traditional continuing education activities change physician behaviour or health care outcomes? JAMA 1999; 282: 867-74.

10.- Polderman K H, Girbes A R J. Central venous catheter use. Part 1: Mechanical complications. Intensive Care Med 2002; 28: 1-17.

11.- Skiest D J, Abbott M, Keiser P. Peripherally inserted central catheters in patients with AIDS are associated with a low infection rate. Clin Infect Dis 2000; 30: 949-52

12.- Lam S, Scannell R, Roessler D, Smith M A. Peripherally inserted central catheters in an acute care hospital. Arch Intern Med 1994; 154: 1833-7.

13.- Ng P K, Ault M J, Ellrodt A G, Maldonado L. Peripherally inserted central catheters in general medicine. Mayo Clinic Proc 1997; 72: 225-33.

14.- Ng P K, Ault M J, Maldonado L S. Peripherally inserted central catheters in the intensive care unit. J Intensive Care Med 1996; 11: 49-54.

15.- Crowley J J, Pereira J K, Harris L S, Becker C J. Peripherally inserted central catheters: experience in 523 children. Radiology 1997; 204: 617-21.

16.- Donovan M S, Thomas K D, Davis D C, Hawkins K, Harris D S. Peripherally inserted central catheters: placement and use in a family practice hospital. J Am Board Fam Pract 1996; 9: 235-40.

17.- Abi-Nader J A. Peripherally inserted central venous catheters in critical care patients. Heart Lung 1993; 22: 428-34.

18.- Loewenthal M R, Dobson P M, Starkey R E, Dagg S A, Petersen A, Boyle M J. The peripherally inserted central catheters (PICC): a prospective study of its 
natural history after cubital fossa insertion. Anaesth Intensive Care 2002; 30: 21-4.

19.- Strahilevitz J, Lossos I S, Verstandig A, Sasson T, Kori Y, Gillis S. Vascular access via peripherally inserted central venous catheters: experience in 40 patients with acute leukemia. Leuk Lymphoma 2001; 40: 365-7.

20.- Chung D H, Ziegler M M. Central venous catheter access. Nutrition 1998; 14: 19-23.

21.- Cowl C T, Weinstock J V, Al-Jurf A, Ephgrave K, Murray J A, Dillon K. Complications and cost associated with parenteral nutrition delivered to hospitalized patients through either subclavian or peripherically inserted catheter. Clin Nutr 2000; 19: 237-43.

22.- Duerksen D R, Papineau N, Siemens J, Yaffe C. Peripherally inserted central catheters for parenteral nutrition: a comparison with centrally inserted catheters. JPEN J Parenter Enteral Nutr 1999; 23: 85-9.

23.- Paz-Fumagalli R, Miller Y A, Russell B A, Crain M R, Beres R A, Mewissen M W. Impact of peripherally inserted catheters on phlebitis complications of peripherally intravenous therapy in spinal cord injury patients. J Spinal Cord Med 1997; 20: 341-4.

24.- Griffiths V R, Philpot P. Peripherally inserted central catheters (PICCs): do they have a role in the care of critically ill patients? Intensive Care Nurs 2002; 18: 37-47.

25.- Janes M, Kalyn A, Pinelli J, Paes B. A randomized trial comparing peripherally inserted central venous catheters in infants with very low birth weight. Pediatr Surg 2000; 35: 1040-4.

26.- Snelling R, Jones G, Figueredo A, Major P. Central venous catheters for infusion therapy in gastrointestinal cancer. A comparative study of tunneled centrally placed catheters and peripherically inserted catheters. J Intraven Nurs 2001; 24: 38-47.

27.- Smith J R, Friedell M L, Cheatham M L, Martin S P, Cohen M J, Horowitz J D. Peripherally inserted central catheters revisited. Am J Surg 1998; 176: 20811.

28.- Pardo De La Vega R, Los Arcos Solas M, Ferrero De La Mano L, Medina Villanueva A, Concha Torre A, Rey Galan C. Use of peripherally inserted multilumen catheter as an alternative to central venous catheters. An Esp Pediatr 2002; 57: 18-21.

29.- Horattas M C, Trupiano J, Hopkins S, Pasini D, Martino C, Murty A. Changing concepts in long term central venous access: catheter selection and cost savings. Am J Infect Control 2001; 29: 32-40.

30.- Alhimyary A, Fernández C, Picard M et al. Safety and efficacy of total parenteral nutrition delivered via a peripherically inserted central venous catheter. Nutr Clin Pract 1996; 11: 199-203.

31.- Foo R, Fujii A, Harris J A, LaMorte W, Moulton S. Complications in tunneled CVL versus PICC lines in very low birth weight infants. J Perinatol 2001; 21: 525-30.

32.- Parellada J A Moise A A, Hegemier S, Gest AL. Percutaneous central catheters and peripheral intravenous catheters have similar infection rate in very low birth weight infants. J Perinatol 1999; 19: 251-4.

33.- Cardella J F, Cardella K, Bacci N, Fox P S, Post J H. Cumulative experience with 1273 peripherically inserted central catheters at a single institution. J Vasc Interv Radiol 1996; 7: 5-13.
34.- Chemaly R F, de Parres J B, Rehm S J et al. Venous thrombosis associated with peripherally inserted central catheters: a retrospective analysis of the Cleveland Clinic Experience. Clin Infect Dis 2002; 34: 1179-81.

35.- Randolph A G, Cook D J, Gonzales C A, Brun-Bruisson C. Tunneling short-term central venous catheters to prevent catheter-related infection. A meta-analysis of randomized, controlled trials. Crit Care Med 1998; 26: $1452-7$.

36.- Timsit J F, Sebille V, Farkas J C et al. Effect of subcutaneous tunneling on internal jugular catheterrelated sepsis in critically ill patients. JAMA 1996; 276: 1416-57.

37.- Timsit J F, Bruneel F, Chevall C et al. Use of tunneled femoral catheters to prevent catheter-related infections. A randomized, controlled trial. Ann Intern Med 1999; 130: 729-35.

38.- Nahum E, Levy I, Katz J et al. Efficacy of subcutaneous tunneling for prevention of bacterial colonization of femoral central venous catheters in critically ill children. Pediatr Infect Dis J 2002; 21: 1000-4.

39.- Ruesch S, Walder B, Tramer M R. Complications of central venous catheters: internal jugular versus subclavian access. A systematic review. Crit Care Med 2002; 30: 454-80.

40.- Merrer J, De Jonghe B, Golliot F et al. Complications of femoral and subclavian venous catheterization in critically ill patients. A randomized controlled trial. JAMA 2001; 286: 700-7.

41.- Cimochowski G E, Warley E, Rutherford W E, Sartain J A, Blondin J, Harter H. Superiority of the internal jugular over the subclavian access for temporary dialysis. Nephron 1990; 54: 154-61.

42.- Kamal G D, Pfaller M A, Rempe L E, Jebson P J. Reduced intravascular catheter infection by antibiotic bonding. A prospective, randomized, controlled trial. JAMA 1991; 265: 2364-8.

43.- Veenstra D L, Saint S, Saha S, Lumley T, Sullivan S D. Efficacy of antiseptic-impregnated central venous catheters in preventing catheter-related bloodstream infection. A meta-analysis. JAMA 1999; 281: 261-7.

44.- Maki D G, Stolz S M, Wheeler S, Mermel L A. Prevention of central venous catheter-related bloodstream infection by use of an antiseptic-impregnated catheter. A randomized, controlled trial. Ann Intern Med 1997; 127:257-66.

45.- Marin M G, Lee J C, Skurnic J H. Prevention of nosocomial bloodstream infections: effectiveness of antimicrobial-impregnated and heparin-bonded central venous catheters. Crit Care Med 2000; 28: 3332-8.

46.- Raad II, Darouiche R, Dupuis J et al. Central venous catheters coated with minocycline and rifampin for the prevention of catheter-related colonization and bloodstream infections. A randomized, double-blind trial. Ann Intern Med 1997; 127: 267-74.

47.- Logghe C, Van Ossel C, D'Hoore W, Ezzedine H, Wauters G, Haxhe J J. Evaluation of clorhexidine and silver-sulfadiazine impregnated central venous catheters for the prevention of bloodstream infection in leukaemic patients: a randomized controlled trial. J Hosp Infect 1997; 37: 145-56.

48.- Darouiche R O, Raad II, Heard S O et al. A comparison of two antimicrobial-impregnated central venous catheters. Catheter Study Group. N Engl J Med 1999; 340: $1-8$.

49.- Veenstra D L, Saint S, Sullivan S D. Cost-effectiveness of antiseptic-impregnated central venous catheters 
for the prevention of catheter-related bloodstream infection. JAMA 1999; 282: 554-60.

50.- Gilliam C. $28^{\text {th }}$ Educational Conference of the Association for Professionals in Infection Control and epidemiology Seattle, WA. June 2001.

51.- Harel L, Amir J, Livni E, Straussberg R, Varsano I. Serum-sickness-like reaction associated with minocycline therapy in adolescents. Ann Pharmacother 1996; 30: 481-3.

52.- Garland J S, Alex C P, Mueller C D, Cisler-Kahill L A. Local reactions to a chlorhexidine gluconateimpregnated antimicrobial dressing in very low birth weight infants. Pediatr Infect Dis J 1996; 15: 912-14.

53.- Schutze G E. Antimicrobial-impregnated central venous catheters. Pediatr Infec Dis J 2002; 21: 63-4.

54.- Yeung C, May J, Hughes R. Infection rate for single lumen vs triple lumen subclavian catheters. Infect Control Hosp Epidemiol 1988; 9: 154-8.

55.- McCarthy M C, S Hives J K, Robison R J, Broadier T A. Prospective randomized evaluation of single and triple lumen catheters in total parenteral nutrition. JPEN J Parenter Enteral Nutr 1987; 11: 259-62.

56.- Ma T Y, Yoshinaka R, Banaag A, Johnson B, Davis $\mathrm{S}$, Berman S. Total parenteral nutrition via multilumen catheters does not increase the risk of catheter related sepsis: a randomized, prospective study. Clin Infect Dis 1998; 27: 500-3.

57.- Johnson B, Rypins E. Single-lumen vs double lumen catheters for total parenteral nutrition. A randomized, prospective trial. Arch Surg 1990; 125: 990-2.

58.- Gupta S, Batra Y K, Puri G D, Panigrahi D, Roy S. Infection rates in single and double lumen central venous catheters in critically ill patients. Natl Med J India 1995; 8: 114-7.

59.- Farkas J C, Liu N, Bleriot J P, Chevret S, Goldstein F $\mathrm{W}$, Carlet J. Single- versus triple-lumen central catheter-related sepsis: a prospective randomized study in a critically ill population. Am J Med 1992; 93: $277-82$

60.- Lee R B, Buckner M, Sharp K W. Do multi lumen catheters increase central venous catheters sepsis compared to a single lumen catheters. J Trauma 1988; 28: $1472-5$.

61.- Early T F, Gregory R T, Wheeler J r, Snyder S O, Gayle R G. Increased infection rate en double lumen vs single lumen Hickman catheters in cancer patients. South Med J 1990; 83: 34-6.

62.- Shinefield H, Black S, Fattom A et al. Use of a Staphylococcus aureus conjugate vaccine in patients receiving hemodialysis. N Engl J Med 2002; 346: 491-6.

63.- Randolph A G, Cook D J, Gonzales C A, Pribble C G. Ultrasound guidance for placement of central venous catheters: a meta-analysis of the literature. Crit Care Med 1996; 24: 2053-8.

64.- Mannel R S, Manetta A, Hickman R L Jr, Walker J L, Berman M L, DiSaia P J. Cost analysis of Hickman catheter insertion at bedside in gynecologic oncology patients. J Am Coll Surg 1994; 179: 558-60.

65.- Holloway R W, Orr J W. An evaluation of Groshong central venous catheters on a gynecologic oncology service. Gynecol Oncol 1995; 56: 211-7.

66.- Finney R, Albrink M H, Hart M B, Rosemurgy A S. A cost-effective peripheral venous port system placed at the bedside. J Surg Res 1992; 53: 17-19.

67.- Raad H, Hohn D C, Gilbreath J et al. Prevention of central venous catheter-related infections by using maximal sterile barrier precautions during insertion.
Infect Control Hosp Epidemiol 1994; 15: 231-8.

68.- Chaiyakunapruk N, Veenstra D L, Lipsky B A, Saint S. Chlorhexidine compared with povidone-iodine solution for vascular catheter-site care: a metaanalysis. Ann Intern Med 2002; 136: 792-801.

69.- Fong I W. Prevention of haemodialysis and peritoneal dialysis catheter related infection by topical povidoneiodine. Postgrad Med J 1993; 69 Suppl 3: S15-7.

70.- Levin A, Mason A J, Jindal K K, Fong I W, Goldstein M B. Prevention of hemodialysis subclavian vein catheter infections by topical povidone-iodine. Kidney Int 1991; 40: 934-8.

71.- Garland J S, Alex C P, Mueller C D et al. A randomized trial comparing povidone-iodine to a chlorhexidine gluconate-impregnated dressing for prevention of central venous catheter infections in neonates. Pediatrics 2001;107: 1431-6.

72.- Lefrant J Y, Muller L, De La Coussaye J E et al. Risk factors of failure and immediate complication of subclavian vein catheterization in critically ill patients. Intensive Care Med 2002; 28: 1036-41.

73.- Hoffmann K K. Transparent polyurethane film as an intravenous catheter dressing. A meta-analysis of the infection risks. JAMA 1992; 267: 2072-6.

74.- Lau C E. Transparent and gauze dressings and their effect on infection rates of central venous catheters: a review of past and current literature. J Intraven Nurs 1996; 19: 240-5.

75.- Conly J M, Grieves K, Peters B. A prospective, randomized study comparing transparent and dry gauze dressings for central venous catheters. J Infect Dis 1989; 159: 310-9.

76.- Maki D G, Stolz S S, Wheeler S, Mermel L A. A prospective, randomized trial of gauze and two polyurethane dressings for site care of pulmonary artery catheters: implications for catheter management. Crit Care Med 1994; 22: 1729-37.

77.- Shivnan J C, McGuire D, Freedman S et al. A comparison of transparent adherent and dry sterile gauze dressings for long-term central catheters in patients undergoing bone marrow transplant. Oncol Nurs Forum 1991; 18: 1349-56.

78.- Young G P, Alexeyeff M, Russell D M, Thomas R J. Catheter sepsis during parenteral nutrition: the safety of long-term OpSite dressings. JPEN J Parenter Enteral Nutr 1988; 12: 365-70.

79.- Andersen P T Herlevsen P, Schaumburg H. A comparative study of 'Op-site' and 'Nobecutan gauze' dressings for central venous line care. J Hosp Infect 1986; 7 : 161-8.

80.- Little K, Palmer D. Central line exit sites: which dressing? Nurs Stand 1998; 12: 42-4.

81.- Reynolds M G, Tebbs S E, Elliott T S. Do dressings with increased permeability reduce the incidence of central venous catheter related sepsis? Intensive Crit Care Nurs 1997; 13: 26-9.

82.- Cook D, Randolph A, Kennerman P et al. Central venous catheter replacement strategies: a systematic review of the literature. Crit Care Med 1997; 25: 1417-24.

83.- Eyer S, Brummitt C, Crossley K, Siegel R, Cerra F. Catheter-related sepsis: prospective, randomized study of three method of long-term catheter maintenance. Crit Care Med 1990; 18: 1073-9.

84.- Cobb D K, High K P, Sawyer R G et al. A controlled trial of scheduled replacement of central venous and pulmonary-artery catheters. N Engl J Med 1992; 327: 1062-8. 
85.- Uldall P R, Merchant N, Woods E, Yarworski U, Vas S. Changing subclavian haemodialysis cannulas to reduce infection. Lancet 1981; 1 (8234): 1373.

86.- Timsit J F, Farkas J F, Boyer J M et al. Central vein catheter-related thrombosis in intensive care patients. Incidence, risks factors, and relationship with catheter related sepsis. Chest 1998; 114: 207-13.

87.- Randolph A, Cook D, Gonzales C, Andrew M. Benefit of heparin in central venous and pulmonary artery catheters. A meta-analysis of randomized controlled trials. Chest 1998; 113: 165-171.

88.- Bern M M, Lokich J J, Wallach S R et al. Very low doses of warfarin can prevent thrombosis in central venous catheter. A randomized prospective trial. Ann Inter Med 1990; 112: 423-8.

89.- Boraks P, Seale J, Price J et al. Prevention of central venous catheter associated thrombosis using minidose warfarin in patients with haematological malignancies. Br J Haematol 1998; 101: 483-6.

90.- Mermel L A. Prevention of intravascular catheterrelated infections. Ann Intern Med 2000; 132: 391 402.

91.- Kacica M A, Horgan M J, Ochoa L, Sandler R, Lepow M L, Venezia R A. Prevention of gram-positive sepsis in neonates weighing less than 1500 grams. J Pediat 1994; 125: 253-8.

92.- Spafford P S, Sinkin R A, Cox C, Reubens L, Powell K R. Prevention of central venous catheter-related coagulase-negative staphylococcal sepsis in neonates. J Pediatr 1994; 125: 259-63.

93.- $\operatorname{Raad} H$, Hachem R Y, Abi-Said D et al. A prospective crossover randomized trial of novobiocin and rifampin prophylaxis for the prevention of intravascular catheter infections in cancer patients treated with interleukin-2. Cancer 1998; 82: 403-11.

94.- Hill R L, Fisher A P, Ware R J, Wilson S, Casewell M W. Mupirocin for the reduction of colonization of internal jugular cannulae. A randomized controlled trial. J Hosp Infect 1990; 15: 311-21.

95.- Sesso R, Barbosa D, Leme I L et al. Staphylococcus aureus prophylaxis in hemodialysis patients using central venous catheter: effect of mupirocin ointment. J Am Soc Nephrol 1998; 9: 1085-92.

96.- Zakrzewska-Bode A, Muytjens H L, Liem K D, Hoogkamp-Korstanje J A. Mupirocin resistance in coagulase-negative staphylococci, after topical prophylaxis for the reduction of colonization of central venous catheters. J Hosp Infect 1995; 31: 189-93.

97.- Miller M A, Dascal A, Portnoy J, Mendelson J. Development of mupirocin resistance among methicillin-resistant Staphylococcus aureus after widespread use of nasal mupirocin ointment. Infect Control Hosp Epidemiol 1996; 17: 811-3.

98.- Henrickson K J, Axtell R A, Hoover S M et al. Prevention of central venous catheter-related infections and thrombotic events in immunocompromised children by the use of vancomycin/ciprofloxacin/ heparin flush solution: A randomized, multicenter, double-blind trial. J Clin Oncol 2000; 18: 1269-78.

99.- Schwartz C, Henrickson K J, Roghmann K, Powell $\mathrm{K}$. Prevention of bacteremia attributed to luminal colonization of tunneled central venous catheters with vancomycin-susceptible organisms. J Clin Oncol 1990; 8:1591-7.

100.-Rackoff W R, Weiman M, Jakobowski D et al. A randomized, controlled trial of the efficacy of a heparin and vancomycin solution in preventing central venous catheter infections in children. J Pediatr
1995; 127: 147-51

101.-Carratalá J, Niubo J, Fernández-Sevilla A et al. Randomized, double-blind trial of an antibiotic-lock technique for prevention of Gram positive central venous catheter-related infection in neutropenic patients with cancer. Antimicrob Agents Chemother 1999; 43: 2200-4.

102.- Boelaert J R, De Smedt R A, De Baere Y A et al. The influence of calcium mupirocin nasal ointment on the incidence of Staphylococccus aureus infections in haemodialysis patients. Nephrol Dial Transplant 1989; 4: 278-81.

103.- Dogra G K, Herson H, Hutchison B et al. Prevention of tunneled hemodialysis catheter-related infections using a catheter-restricted filling with gentamicin and citrate: a randomized controlled study. J Am Soc Nephrol 2002; 13: 2133-9.

104.-Maki D G, Rhame F S, Mackel D C, Bennett J V. Nationwide epidemic of septicemia caused by contaminated intravenous products, 1. Epidemiologic and clinical features. Am J Med 1976; 60: 471-85.

105.-Buxton A E, Highsmith A K, Garner J S et al. Contamination of intravenous infusion fluid: Effects of changing administration sets. Ann Intern Med 1979; 90: 764-8.

106.- Band J D, Maki D G. Safety of changing intravenous delivery systems at longer than 24 hour intervals. Ann Intern Med 1979; 90: 173-8.

107.- Snydman D R, Donelly-Reidy M, Perry L K, Martin W J. Intravenous tubing contaning burettes can be safely changes at 72 hour intervals. Infect Control 1987; 8: 113-6.

108.- Josephson A, Gombert M E, Sierra M F, Karantil L $\mathrm{V}$, Tansino G F. The relationship between intravenous fluid contamination and the frequency of tubing replacement. Infect Control 1985; 6: 367-70.

109.- Maki D G, Botticelli J T, LeRoy M L, Thielke T S. Prospective study of replacing administration sets for intravenous therapy at 48- vs 72-hour intervale: 72 hours is safe and cost-effective. JAMA 1987; 258: 1777-81.

110.- Gorbea H F, Snydman D R, Delaney A, Stockman J, Martin W J. Intensive care patients may have intravenous tubing with burettes safely changed at 48 hour intervals. JAMA 1984; 251: 2112-5.

111.- Josephson A. Changing intravenous tubing containing burettes. JAMA 1985; 253: 42-3.

112.- Raad I, Hend A, Awad A et al. Optimal frequency of changing intravenous administration sets. Is it safe to prolong use beyond 72 hours? Infect Control Hosp Epidemiol 2001; 22: 136-9.

113.- Sitges-Serra A, Linares J, Pérez J L, Jaurrieta E, Lorente L. A randomized trial on the effect of tubing changes on hub contamination and catheter sepsis during parenteral nutrition. Parenter Enteral Nutr 1985; 9: 322-5.

114.- Melly MA, Meng HC, Schaffner W. Microbial growth in lipid emulsions used in parenteral nutrition. Arch Surg 1975; 110: 1479-81.

115.- Mershon J, Nogami W, Williams J M, Yoder C, Eitzen $\mathrm{H}$ E, Lemons J A. Bacterial/ fungal growth in a combined parenteral nutrition solution. JPEN J Parenter Enteral Nutr 1986; 10: 498-502.

116.-Didier M E, Fisher S Maki D G. Total nutrient admixtures appear safer than lipid emulsion alone as regards microbial contamination: growth properties of microbial pathogens at room temperature. JPEN J Parenter Enteral Nutr 1998; 22: 291-6. 
117.--Mendelson M H, Short L J, Schechter C B et al. Study of a needleless intermitent intravenous- access system for peripheral infusions, analysis of staff, patient, and institutional outcomes. Infect Control Hosp Epidemiol 1998; 19: 401-6.

118.-Seymour V M, Dhallu T S, Moss H A, Tebbs S E, Elliot T S. A prospective clinical study to investigate the microbial contamination of a needleless connector. J Hosp Infect 2000; 45: 165-8.

119.- Arduino M J, Bland L A, Danzig L E, McAllister S K, Aguero S M. Microbiologic evaluation of needlelessaccess devices. Am J Infect Control 1997; 25: 377 80 .

120.-Luebke M A, Arduino M J, Duda D L et al. Comparison of the microbial barrier properties of a needleless and a conventional needle - based intravenous access system. Am J Infect Control 1998; 26: 437-41.

121.- Cookson S T, Ihrig M, O`Mara E M et al. Increased bloodstream infection rates in surgical patients associated with variation from recommended use and care following implementation of a needleless device. Infect Control Hosp Epidemiol 1998; 19: 23-7.

122.- Cohen Y, Fosse J P, Karoubi P et al. The "handsoff" catheter and prevention of systemic infections associated with pulmonary artery catheter. A prospective study. Am J Respir Crit Care Med 1998; 157: 284-7.

123.-Maki D G, McCormack K N. Defatting catheter insertion sites in total parenteral nutrition is of no value as an infection control measure. Am J Med 1987; 83: 833-40.

Correspondencia a:

Alberto Fica Cubillos

E-mail: afica@ns.hospital.uchile.cl 